\title{
Adsorption and Desorption Behavior of Herbicide Mefenpyr- diethyl in the Agricultural Soils of Morocco
}

\author{
Abdellah El Boukili ${ }^{1, *}$, Nidae Loudiyi ${ }^{2}$, Ahmed El Bazaoui ${ }^{3}$, Abderrahim EL Hourch ${ }^{2}$, Abderrahman \\ EL Boukili ${ }^{4}$ and M'hamed Taibi ${ }^{1}$ \\ ${ }^{2}$ Faculty of sciences, University Mohammed V, Av. Ibn Battouta, BP 1014, Rabat, Morocco \\ ${ }^{3}$ Faculty of Sciences, University Ibn Tofail, LGB, BP, 133, 14000 Kenitra, Morocco \\ ${ }^{4}$ University Ibn Tofail, Sciences de l'ingénieur et Modélisation, BP, 133, 14000 Kenitra, Morocco
}

\begin{abstract}
The present study was conducted in order to investigate the adsorption and desorption behavior of Mefenpyr-diethyl (MFD) using the batch equilibration technique in four soils, with different ranges of organic matter content, from different regions of Morocco orders of Benimellal (Soil 1), Settat (Soil 2), Sidi Bettach (Soil 3) and EL Hajeb (Soil 4). The adsorption isotherm models Langmuir, linear and Freundlich were used to compare the adsorption capacity of the soils. The results indicated that the Freundlich equation provided the best fit for all adsorption data. The values of $\mathrm{K}_{\mathrm{F}}$ and $\mathrm{K}_{\mathrm{d}}$ ranged from 4.45 to 15.9 and 4.30 to $18.30 \mathrm{~L}_{\mathrm{kg}} \mathrm{k}^{-1}$, respectively. The calculated total percentage of desorption values from the Soil 1, Soil 2, Soil 3 and Soil 4 after the four desorption process were $59 \% ; 55,6 \% ; 37,5 \%$ and 52,5\%, respectively. Highest adsorption and desorption were observed in soil 1 , and the lowest was in soil 3 . According to the adsorption and desorption results, organic matter and clay seemed to be the most important factors influencing the adsorption capacity of MFD.
\end{abstract}

Keywords: Adsorption; Chromatography; Desorption; Freundlich; Mefenpyr-diethyl; Soil.

\section{Introduction}

The herbicides have been widely used since 1950s for controlling of broadleaf weeds and annual grasses in agricultural and non-crop fields ${ }^{1}$. A very small fraction of applied herbicides reaches the target weeds, while the large fraction enters the environment, causing soil and water pollutions ${ }^{2}$. Consequently, the herbicides have been detected in the surface and groundwater of the United States, Europe and Australia ${ }^{3,4}$.

The herbicide Mefenpyr-diethyl (MFD) is usually used as a herbicide safener in combination with other herbicides over cereal grain crops to improve herbicide selectivity between crops and weed species. American Society of Plant Biologists has reported MFD as potential carcinogenic herbicides. Owing to their carcinogenic potentials, the presence of these herbicides in water is a cause of concern for public and regulatory agencies ${ }^{5,6,7}$.

Literature suggests that adsorption of herbicide to the soil is the key process that affects their ecotoxicological impact, environmental mobility and the rate of degradation ${ }^{8,9}$. The desorption process of herbicides is also important since it determines the release rate and the potential mobility of herbicides in

*Corresponding author: Abdellah El Boukili

Email address: abdellahelboukili@gmail.com

DOI: http://dx.doi.org/10.13171/mjc7519111210255aeb the soil ${ }^{8}$. The adsorption/desorption process of herbicide is influenced by several factors like organic matter content, soil texture, $\mathrm{pH}$, temperature, etc. ${ }^{8,10}$. The risk of herbicide entering the surface water and groundwater mainly comes from the adsorbed herbicide present in the soil. To protect surface and groundwater from pesticide contamination and evaluate their impact, extensive knowledge concerning degradation and sorption-desorption processes in the environment is required ${ }^{10,11}$.

Currently, the adsorption-desorption phenomena of pollon on different adsorbents are a growing concern among researchers around the world ${ }^{12,13,14,15,16}$. In Morocco, due to the increased use of pesticides in the agricultural sector, adsorptiondesorption studies of pesticides have been published, such as isoproturon 17, Tribenuron-methyl ${ }^{18}$, imazethapyr ${ }^{19}$, metalaxyl, tricyclazole ${ }^{20}$ and MFD on $\mathrm{TiO} 2$ photocatalytic materials ${ }^{7}$, have been published. However, no studies on the adsorption of MFD on agricultural soils have been carried out so far.

This work aimed to determine adsorptiondesorption behavior of herbicide Mefenpyr-diethyl in the agricultural cereal soils, at natural $\mathrm{pH}$, of Moroccan. Factors affecting the 
adsorption efficiency of herbicides such as contact time and initial concentration of the solution were studied. The kinetics and adsorption isotherms of MFD have been conducted in order to understand the adsorption mechanism. The evolution of different concentrations was monitored by GC/MS. The adsorption isotherm models Langmuir and Freundlich were used to compare the adsorption capacity of the soils.

\section{Materials \& Methods}

Chemicals

Mefenpyr-diethyl (Figure 1) was supplied by Sigma-Aldrich (Germany) as analytical standards with purity $>97 \%$. The stock solution of Mefenpyrdiethyl $\left(1000 \mu \mathrm{g} \mathrm{mL}^{-1}\right)$ was prepared in methanol and kept at $4^{\circ} \mathrm{C}$ before analysis. All reagents used were of analytical grade, as if methanol, dichloromethane and chemical, sodium sulfate $\left(\mathrm{Na}_{2} \mathrm{SO}_{4}\right)$, calcium chloride $\left(\mathrm{CaCl}_{2}\right)$ were procured from Merck (Darmstadt, Germany). Purified water was prepared using a MilliQ water purification system (Millipore, Bedford, Ma) for high-performance liquid chromatography (HPLC) analysis. All stock solutions were stored in a refrigerator at $4^{\circ} \mathrm{C}$. The physicochemical properties of Mefenpyr-diethyl safener herbicide are cited in (Table 1).<smiles>CCOC(=O)C1=NN(c2ccc(Cl)cc2Cl)C(C)(C(=O)OCC)C1</smiles>

Figure 1. Chemical structure of MFD (Mefenpyr-diethyl)

Table 1. Some important physicochemical properties of Mefenpyr-diethyl.

\begin{tabular}{|l|l|}
\hline IUPAC: diethyl (RS)-1-(2,4-dichlorophenyl)-5-methyl-2-pyrazoline-3,5-dicarboxylate \\
\hline Molecular Weight & $373.23 \mathrm{~g} \cdot \mathrm{mol}^{-1}$ \\
\hline Molecular formula & $\mathrm{C}_{16} \mathrm{H}_{18} \mathrm{Cl}_{2} \mathrm{~N}_{2} \mathrm{O}_{4}$ \\
\hline Purity & $99.2 \%$ \\
\hline Solubility in water $\left(\mathrm{pH}=6,1 ; 25^{\circ} \mathrm{C}\right)$ & $20 \mathrm{mg} . \mathrm{L}^{-1}$ \\
\hline Solubility in dichloromethane & $500 \mathrm{~g} . \mathrm{L}^{-1}$ \\
\hline Solubility in methanol & $400 \mathrm{~g} . \mathrm{L}^{-1}$ \\
\hline
\end{tabular}

\section{Soil characteristics}

For soil, samples used in this study were collected from agricultural fields and contained no detectable amount of mefenpyrdiethyl residues. Samples taken from the plow layer $(0-30 \mathrm{~cm})$, were air dried at room temperature, mixed thoroughly, and sieved through $2 \mathrm{~mm}$ mesh. Some physical and chemical properties of the soils were determined and are summarized in
Table 2. Soil $\mathrm{pH}$ was measured by mixing $10 \mathrm{~g}$ of dry soil and $10 \mathrm{ml}$ of deionized water, after one hour of contact time the $\mathrm{pH}$ of the slurry was measured using Orion 420 plus $\mathrm{pH}$ meter equipped with a glass electrode ${ }^{21,22}$. The soil organic carbon was measured by oxidation method with $\mathrm{K}_{2} \mathrm{Cr}_{2} \mathrm{O}_{7}-\mathrm{H}_{2} \mathrm{SO}_{4}$. The surface area is measured by the Blaine method ${ }^{23,24}$.

Table 2. The physical and chemical properties of the tested soils.

\begin{tabular}{|c|c|c|c|c|c|c|c|c|c|c|}
\hline \multirow{2}{*}{ Soil } & \multirow{2}{*}{ Region } & \multirow{2}{*}{ Latitude } & \multirow{2}{*}{ pH } & \multirow{2}{*}{$\begin{array}{c}\text { Surface } \\
\text { area } \\
\left(\mathrm{cm}^{2} / \mathrm{g}\right)\end{array}$} & \multirow{2}{*}{$\begin{array}{c}\% \\
\mathrm{CO}\end{array}$} & \multirow{2}{*}{$\begin{array}{c}\% \\
\text { Organic } \\
\text { matter }\end{array}$} & \multicolumn{4}{|c|}{ Particles Size (\%) } \\
\hline & & & & & & & Sand & Silt & Clay & Texture \\
\hline 1 & $\begin{array}{l}\text { Benimellal } \\
\text { Souk Sebt }\end{array}$ & $\begin{array}{c}32.3333^{\circ} \\
(-6.35)\end{array}$ & 8.2 & 775 & 3.6 & 6.2 & 11 & 60 & 29 & Clay Silt \\
\hline 2 & $\begin{array}{c}\text { Settat } \\
\text { Sidi el aidi }\end{array}$ & $\begin{array}{c}33.1206^{\circ} \\
(-7.59)\end{array}$ & 8.6 & 845 & 3.2 & 5.5 & 50 & 46 & 4 & Silt Loam \\
\hline 3 & $\begin{array}{c}\text { Sidi } \\
\text { Bettach }\end{array}$ & $\begin{array}{c}33^{\circ} 33^{\prime} 58.1^{\prime \prime} \\
\text { N 6 } 6^{\circ} 53^{\prime}\end{array}$ & 7.4 & 720 & 1.8 & 3.1 & 81 & 16 & 3 & Loam \\
\hline 4 & $\begin{array}{l}\text { Meknes } \\
\text { EL Hajeb }\end{array}$ & $\begin{array}{l}33.68573^{\circ} \\
(-5.3677)\end{array}$ & 6.4 & 2996 & 2.2 & 3.7 & 35 & 51 & 14 & Silt Clay \\
\hline
\end{tabular}


Adsorption studies

Adsorption equilibrium time studies

Adsorption experiments were carried out by the standard batch equilibration method, using the batch equilibration technique ${ }^{25}$. To minimize charges in ionic strength and to avoid dispersion, $0.01 \mathrm{M}$ of $\mathrm{CaCl}_{2}$ was used as the background solution [26]. The experiment was conducted at the original $\mathrm{pH}$ value of each soil type. The tests were conducted in triplicate. One gram of soil was weighed separately in $40 \mathrm{~mL}$ conical centrifuge bottles containing $25 \mathrm{~mL} 0.01 \mathrm{M}$ $\mathrm{CaCl}_{2}$ solution and MFD concentration of $5.0 \mu \mathrm{g} . \mathrm{mL}$ ${ }^{1}$. The mixtures were shaken on a horizontal orbital shaker at $150 \mathrm{rpm}$ time intervals were at $0.50 ; 1.0 ; 1.5$; $2.0 ; 7.0 ; 16 ; 24 ; 44$ and $72 \mathrm{~h}$. The temperature of the orbital shaker was set at $22 \pm 0.1{ }^{\circ} \mathrm{C}$ to stimulate the normal conditions. Next, the suspensions were centrifuged at $3000 \mathrm{rpm}$ for $20 \mathrm{~min}$, and the supernatant was mixed with $20 \mathrm{~mL}$ of dichloromethane. The obtained mixture was then settled. The recovered organic phase was dried with dry magnesium sulfate, filtered and stored at $4.0^{\circ} \mathrm{C}$ until analysis by chromatography GC /MS. The amount of MFD adsorbed for each sampling time was calculated from the difference between the initial and equilibrium solution concentrations.

\section{Adsorption isotherms studies}

Batch equilibrium isotherms were determined for all soils under study at $22 \pm 0.1^{\circ} \mathrm{C}$. One gram of airdried soil was placed in $40 \mathrm{~mL}$ conical centrifuge bottles and equilibrated with $25 \mathrm{~mL}$ of $0.01 \mathrm{~mol}$. $\mathrm{L}^{-1}$ $\mathrm{CaCl}_{2}$ solution containing different concentrations of MFD $1.0 ; 1.5 ; 2.0 ; 2.5 ; 3.0 ; 3.5 ; 4.0$ and $4.5 \mu \mathrm{g} . \mathrm{mL}^{-1}$. The mixtures were shaken on a horizontal orbital shaker at $150 \mathrm{rpm}$ for adsorption equilibrium time. After equilibration, the suspensions were centrifuged, the supernatant was mixed with $20 \mathrm{~mL}$ of dichloromethane. The obtained mixture was then settled. The recovered organic phase was dried with dry magnesium sulfate, filtered and stored at $4.0{ }^{\circ} \mathrm{C}$ until analysis by GC/MS.

\section{Desorption studies}

Desorption experiments were performed immediately after the adsorption experiments. After the supernatant samples were decanted, $20 \mathrm{~mL}$ fresh $0.01 \mathrm{M} \mathrm{CaCl}_{2}$ solution (without Mefenpyr-diethyl) was added into the same centrifuge bottles. The mixtures were shaken on a horizontal shaker at 150 rpm for $24 \mathrm{~h}$. The suspensions were centrifuged at $3000 \mathrm{rpm}$ for $20 \mathrm{~min}$, and $1.0 \mathrm{~mL}$ aliquot was filtered before analysis. The process was repeated three times consecutively.

\section{GC/MS analysis}

The GC/MS analysis was carried out on Perkin Elmer Clarus Autosystem Gas Chromatograph/Turbomass Mass Spectrometer instrument operating in electron impact (EI) ionization mode at $70 \mathrm{eV}$, with MS transfer line temperature: $280^{\circ} \mathrm{C}$, ion source temperature: $230^{\circ} \mathrm{C}$, quadrupole temperature: $150^{\circ} \mathrm{C}$. In the full-scan mode, the scanned mass range was 50-400 amu with a scan rate of 1.56 scans /s. The solvent delay was set to $5 \mathrm{~min}$. An HP-5MS column (Hewlett Packard, Palo Alto, CA, USA) $(30 \mathrm{~m} \times 0.25 \mathrm{~mm} \times 0.25 \mu \mathrm{m})$ was used. The flow rate of the carrier gas $(\mathrm{He})$ was $1.0 \mathrm{~mL} . \mathrm{min}-1$. The temperature program was 100 (1 min isotherm) to $260^{\circ} \mathrm{C}$, ramped at $15^{\circ} \mathrm{C} \cdot \mathrm{min}^{-1}$ and hold at the final temperature for $3 \mathrm{~min}$. The injector temperature was $210^{\circ} \mathrm{C}$. The mode of the inlet was split $1 / 20$, and the injected volume was $1 \mu \mathrm{L}$. The total time of analysis was $14.65 \mathrm{~min}$. The identification of the different products was confirmed by comparing the measured mass spectral data with those obtained from the library Nist, as well as literature data $6,7,27,28$.

\section{Data analysis}

Amounts of adsorbed MFD were determined by the mass balance equation, expressed as (Eq1). Where, $\mathrm{q}$ is the specific adsorbed amount of solute $\left(\mathrm{mg} . \mathrm{g}^{-1}\right), \mathrm{V}$ is the volume of the equilibrium solution, $\mathrm{Ci}$ and $\mathrm{C}$ represent the initial concentration and the remaining solution concentration of MFD $\left(\mathrm{mg} \mathrm{L}^{-1}\right)$, respectively, and $\mathrm{m}$ is the mass of the air-dried soil (g).

$q=\frac{V \cdot\left(C_{i}-C\right)}{m}$

The data of MFD adsorption isotherms on both soils can be simulated using the two most commonly used models. The first is the Langmuir model ${ }^{29}$, given in its linear form as Eq 2. The second is the simple empirical model of Freundlich ${ }^{30}$, expressed as follows $\mathrm{Eq} 3$

$$
\begin{aligned}
& \frac{1}{\mathrm{q}_{\mathrm{S}}}=\frac{1}{\mathrm{q}_{\mathrm{Smax}}}+\frac{1}{\mathrm{~K}_{\mathrm{L}} \cdot \mathrm{C}_{\mathrm{e}} \cdot \mathrm{q}_{\mathrm{S} \max }} \\
& \ln \left(\mathrm{q}_{\mathrm{S}}\right)=\ln \left(\mathrm{K}_{\mathrm{F}}\right)+\mathrm{n} \ln \left(\mathrm{C}_{\mathrm{e}}\right)
\end{aligned}
$$

Where, Ce $\left(\mathrm{mg} . \mathrm{L}^{-1}\right)$ is the equilibrium MFD concentration in the solution, and qs is the adsorbed concentrations (mg. $\left.\mathrm{g}^{-1}\right)$. qsmax $\left(\mathrm{mg} . \mathrm{g}^{-1}\right)$ and $\mathrm{K}_{\mathrm{L}}$ $\left(\mathrm{L}_{\mathrm{mg}} \mathrm{m}^{-1}\right.$ ) are the Langmuir constants. $\mathrm{K}_{\mathrm{F}}$ and $\mathrm{n}$ are the adsorption coefficients characterizing the adsorptiondesorption capacity and the Freundlich equation exponent related to the adsorption intensity that is used as an indicator of the adsorption isotherm nonlinearity.

The distribution coefficient $\mathrm{Kd}$, was calculated by linear model as following the equation (4):

$\mathrm{q}_{\mathrm{s}}=\mathrm{K}_{\mathrm{d}} \mathrm{C}_{\mathrm{e}}$

The OC-normalized constant Koc was calculated for adsorption as equation (5), where, \% $\mathrm{OC}$ is the percentage of organic carbon of soil ${ }^{31}$.

$\mathrm{K}_{\mathrm{OC}}=\frac{\mathrm{K}_{\mathrm{d}}}{\% \mathrm{OC}} \cdot 100$ 


\section{Results and Discussion}

\section{Soil characteristics}

As shown in Table 2, the soil characteristics varied widely. The organic carbon content varied from 1.8 to $3.6 \%$. Soil $\mathrm{pH}$ ranged from 6.4 to 8.6 , and clay content varied from 3.0 to $29 \%$. The surface area ranged from 720 to $2996 \mathrm{~cm}^{2} \cdot \mathrm{g}^{-1}$. Among soil properties, the organic carbon content was positively correlated with clay content and silt and was negatively correlated with sand content (Table 3 ). The sand content was negatively correlated with silt. Soil number for showed a higher surface area than soils. The high surface area interpreted by its clay texture; other factors may have an influence namely water ${ }^{32}$, the mineralogical composition and the surface condition of the soil particles ${ }^{33,34,35}$.

Table 3. Correlation coefficients between soil properties for the for soils studied.

\begin{tabular}{|c|c|c|c|c|c|c|}
\hline & pH & $\% \mathrm{CO}$ & area & Sand & Silt & Clay \\
\hline pH & 1 & & & & & \\
\hline$\% \mathrm{OC}$ & 0.758 & 1 & & & & \\
\hline area & -0.834 & -0.392 & 1 & & & \\
\hline Sand & -0.1224 & -0.737 & -0.227 & 1 & & \\
\hline Silt & 0.1611 & 0.755 & 0.298 & -0.963 & 1 & \\
\hline Clay & 0.0426 & 0.597 & 0.081 & -0.906 & 0.758 & 1 \\
\hline
\end{tabular}

\section{Analytical method}

The standard solution of MFD with concentrations of $0.01 ; 2.5 ; 5 ; 10$ and $20 \mu \mathrm{g} . \mathrm{mL}^{-1}$ were prepared by diluting the work standard directly in methanol. Quantitative analysis showed a high degree of linearity with correlation coefficients $\left(R^{2}>0.9994\right)$ over the concentration range of $0.01-20 \mu \mathrm{g} . \mathrm{mL}^{-1}$. The calibration curve was $\mathrm{y}=59949.1 \mathrm{x}+2638.24$, where $\mathrm{y}$ is peak area and $\mathrm{x}$ is MFD concentration.

\section{Adsorption Kinetic}

In the present study, no detectable amount of MFD degradation was found in the supernatant during the adsorption process. Thus, the reduction in the herbicide concentration in the solution was due to soil adsorption. A preliminary adsorption experiment was performed to determine the contact time required for attaining adsorption equilibrium. Figure 2 shows the percent of Mefenpyrdiethyl adsorbed by the soil at different time intervals.

As evident from (Figure 2), the adsorption kinetics exhibited two distinct stages of soils types. The initial step was very rapid adsorption followed by slow adsorption. This observation is because in the initial stage a large number of vacant surface sites were available for adsorption, but once the vacant surfaces were occupied. The repulsive forces between the solute molecules of the solid and bulk phases came into play, thus delaying the adsorption process. A similar observation has been reported for a few other organic herbicides ${ }^{36-37}$.

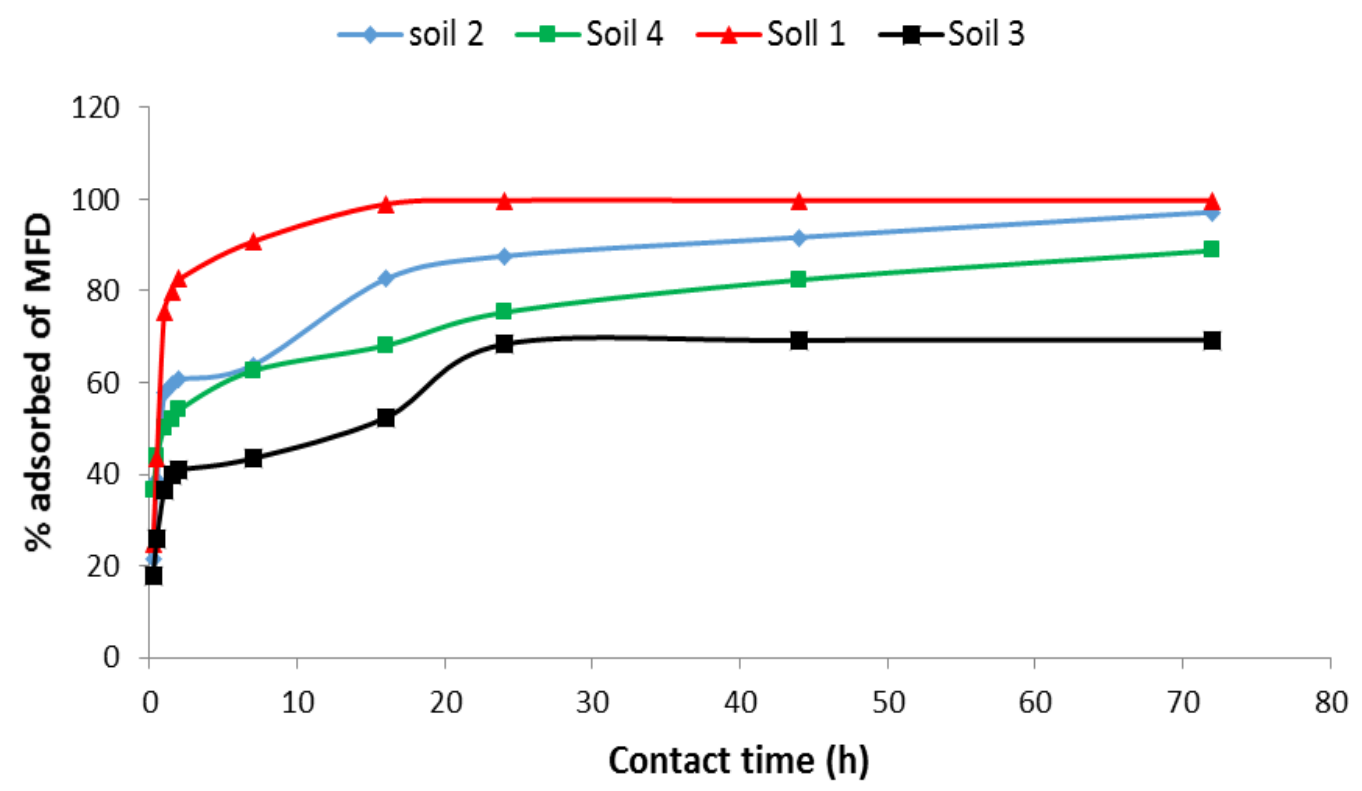

Figure 2. Adsorption kinetics of MFD in soils. (Temperature $=22^{\circ} \mathrm{C} ;[\mathrm{MFD}]_{0}=5.0 \mathrm{mg} \cdot \mathrm{L}^{-1}$, Ratio $=40$ g.L $\mathrm{L}^{-1}$, natural $\mathrm{pH}$ of soil). 
The MFD adsorption equilibrium was reached within $30 \mathrm{~h}$ of incubation in the soils. The maximum of the MFD adsorption was observed in soil 1. This may be due to the high organic matter content in the soil. The (Figure 3) shows that during the first ten minutes of contacting (first step) the soil 4 adsorbs a larger amount of MFD (36.4\%) compared to other soils. It is justified by its large specific surface area.

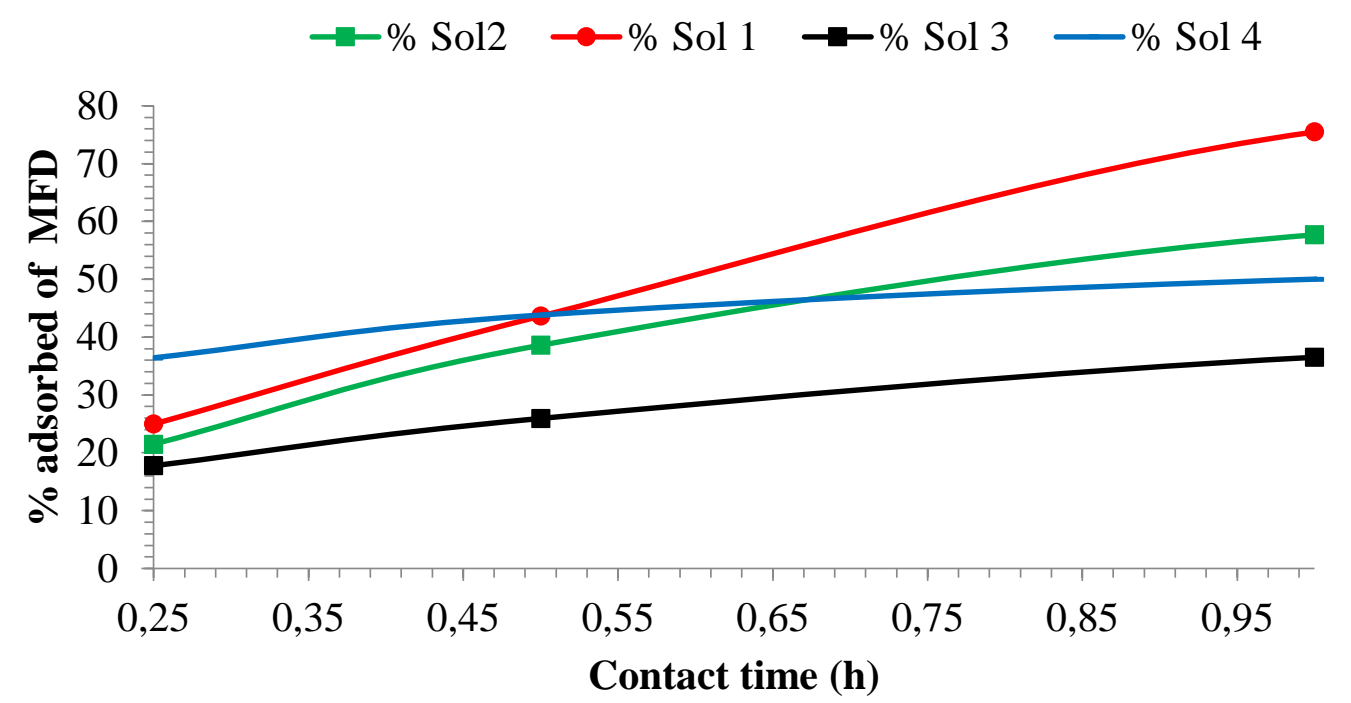

Figure 3. Kinetic adsorption of MFD on soils; first step; (temperature $=22^{\circ}$; $[\mathrm{MFD}]_{0}=5.0 \mathrm{mg} \cdot \mathrm{L}^{-1}$, Ratio $=40$ g.L. $\mathrm{L}^{-1}$, natural $\mathrm{pH}$ of soils)

\section{Adsorption isotherms}

The adsorption isotherms are obtained for the concentrations of MFD ranging from 1.0 to $4.5 \mathrm{mg} . \mathrm{L}^{-1}$ and a liquid to solid ratio of $40 \mathrm{~g} . \mathrm{L}^{-1}$. The contact time between the soil and the herbicide corresponds to the equilibrium time determined in the kinetic study. Two modes of representation of soils were used. The first corresponds to the presentation of herbicide concentrations adsorbed $\mathrm{Cs}$ as a function of initial concentrations $\mathrm{Ci}$. The second is a representation of the adsorbed concentrations based on residual concentrations of the herbicide in equilibrium Ce. The curves obtained are represented in Figure 4 and Figure 5. The analysis of the isotherms (Figure 4) shows, first, no plateau, indicating that the adsorption sites are not saturated in the concentration range of MFD introduced. The adsorbed amount increases with the initial concentration of MDF for different soils. An analysis of the curves (Figure 5) shows that the adsorbed concentration of MFD increases with increasing the concentration of MFD at equilibrium. Giles et al. (1960) classified the adsorption isotherms of the MFD on the soils 1,2 and 3 as L-type (class L, subgroup 1) as the adsorption kinetics corresponded to that of the L-type in the classification ${ }^{38}$. The L-types isotherms represent the system where the solid surface has an average affinity for the herbicide, and the solvent is relatively inert, i.e., there is no strong competition from the solvent for adsorption sites ${ }^{39}$.

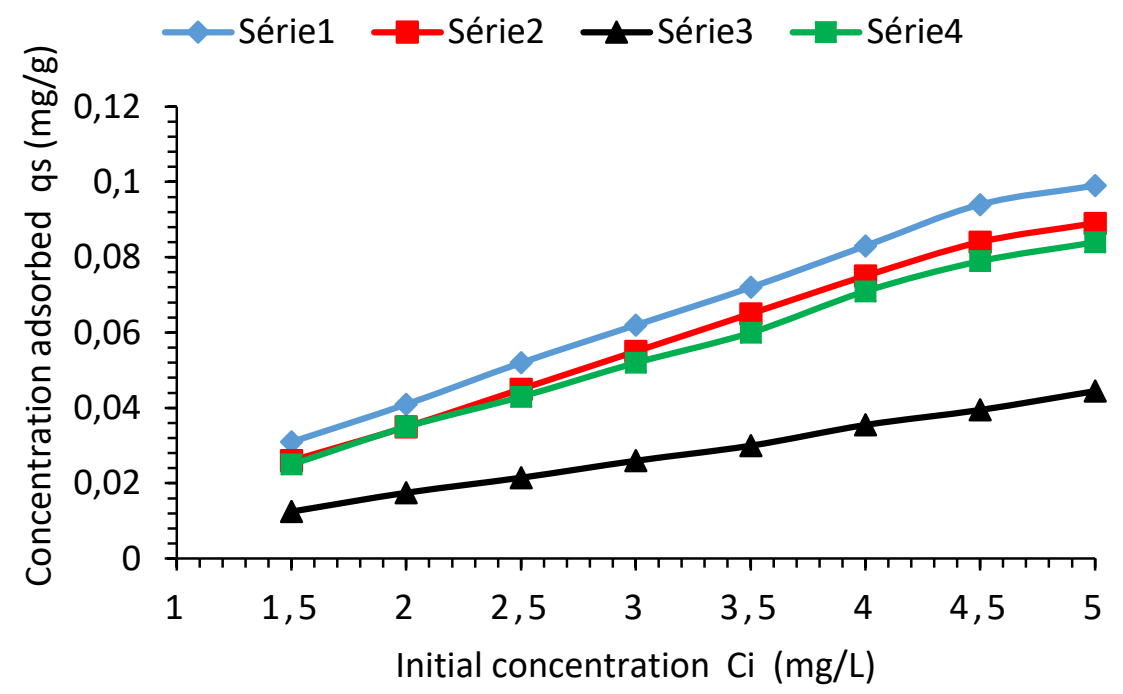

Figure 4. Adsorption isotherms of MFD in soils. (Temperature $=22^{\circ} \mathrm{C}$, ratio $=40 \mathrm{~g} \cdot \mathrm{L}^{-1}$, Time contact $=30 \mathrm{~h}, \mathrm{pH}$ natural of soil) 
This isotherm shape was also reported to fit the adsorption of isoproturon in two Moroccan soils ${ }^{17}$, the adsorption of thiram onto eight Mediterranean soil types typical of Spain ${ }^{40}$ and onto three Indian soil types ${ }^{41}$. Giles et al. classified the adsorption isotherms of the MFD on the soil 4 as C-type (class C, subgroup 1) as the adsorption kinetics corresponded to that of the C-type in the classification ${ }^{38}$. This isotherm shape was also reported to fit the adsorption of MFD in two photocatalytic materials of $\mathrm{TiO} 2$ a savory Degussa P-25 and Hombikat UV100 ${ }^{7}$.

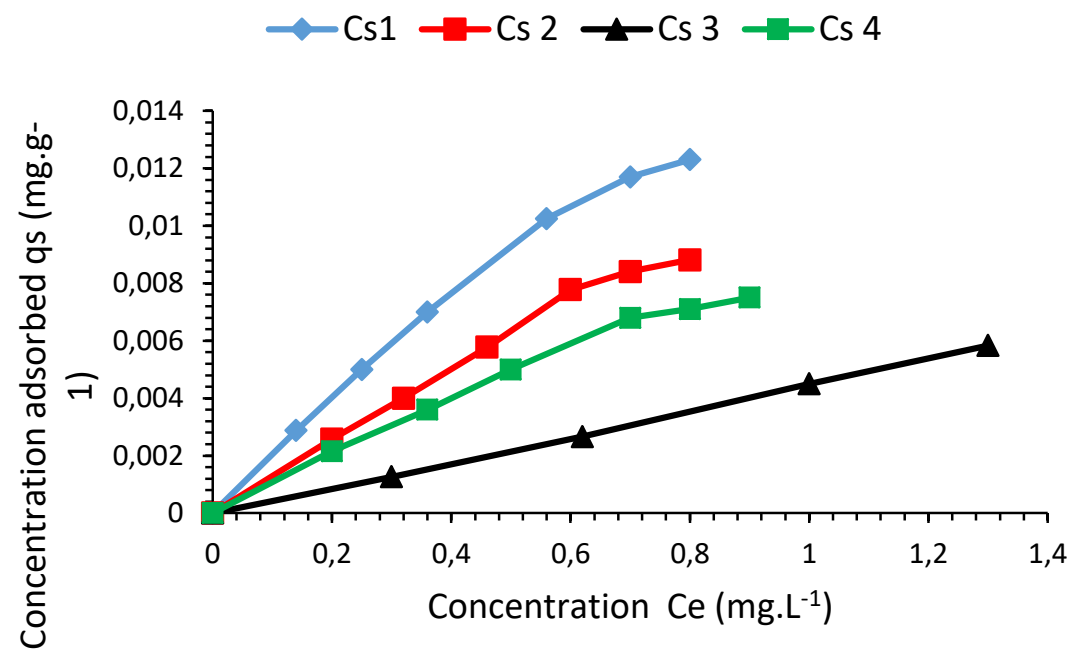

Figure 5. Adsorption isotherms of MFD in soils. (Temperature $=22^{\circ} \mathrm{C}$, ratio $=40 \mathrm{~g} . \mathrm{L}^{-1}$, Time contact $=30 \mathrm{~h}, \mathrm{pH}$ natural of soil)

\section{Adsorption isotherm model}

The simulation parameters of Freundlich and Langmuir Models are determined by the linear plot of $(1 / \mathrm{Cs})$ as a function of $(1 / \mathrm{Ce})$ and $\log (\mathrm{Cs})$ as a function of $\log (\mathrm{Ce})$. The curves obtained are shown in Figures 6 and 7. These parameters and the correlation coefficients were calculated and summarized in Table 4.

Table 4. Langmuir and Freundlich's parameters obtained by linearization of the adsorption isotherms.

\begin{tabular}{|c|c|c|c|c|c|c|} 
Model & \multicolumn{3}{c}{ Langmuir } & \multicolumn{3}{c|}{ Freundlich } \\
\hline Parameters & $\mathrm{K}_{\mathrm{L}}\left(\mathrm{L} \cdot \mathrm{mg}^{-1}\right)$ & $\mathrm{C}_{\mathrm{smax}}\left(\mathrm{mg} \cdot \mathrm{g}^{-1}\right)$ & $\mathrm{R}^{2}$ & $\mathrm{~K}_{\mathrm{F}}\left(\mathrm{L}^{\mathrm{n}} \cdot \mathrm{mg}^{-\mathrm{n}}\right)$ & $\mathrm{n}$ & $\mathrm{R}^{2}$ \\
\hline Soil 1 & 0.414 & 0.0528 & 0.7889 & $15.9 .10^{-6}$ & 0.848 & 0.9928 \\
\hline Soil 2 & 0.154 & 0.0865 & 0.7656 & $11.6 .10^{-6}$ & 0.926 & 0.9909 \\
\hline Soil 3 & N.C & Not calculable & 0.9992 & $8.69 .10^{-6}$ & 0.854 & 0.9926 \\
\hline Soil 4 & 0.361 & 0.032 & 0.7581 & $4.45 .10^{-6}$ & 1.000 & 0.9998 \\
\hline
\end{tabular}

\section{$\Delta 1 / \operatorname{Cs} 1 \square 1 / \operatorname{Cs} 2 \Delta 1 / \operatorname{Cs} 3 \quad \otimes 1 / \operatorname{Cs} 4$}

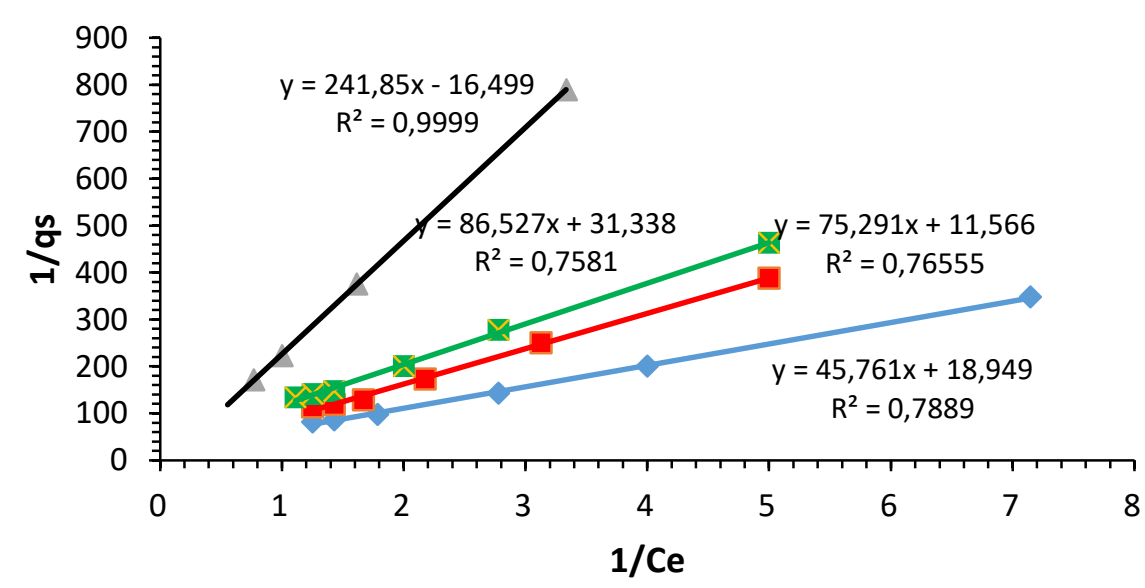

Figure 6. Langmuir adsorption isotherm for MFD adsorbed in Soils (Temperature $=22^{\circ} \mathrm{C}$, Ratio $=40 \mathrm{~g} \cdot \mathrm{L}^{-1}$, Time contact $=30 \mathrm{~h}$, natural $\mathrm{pH}$ of soil $)$ 


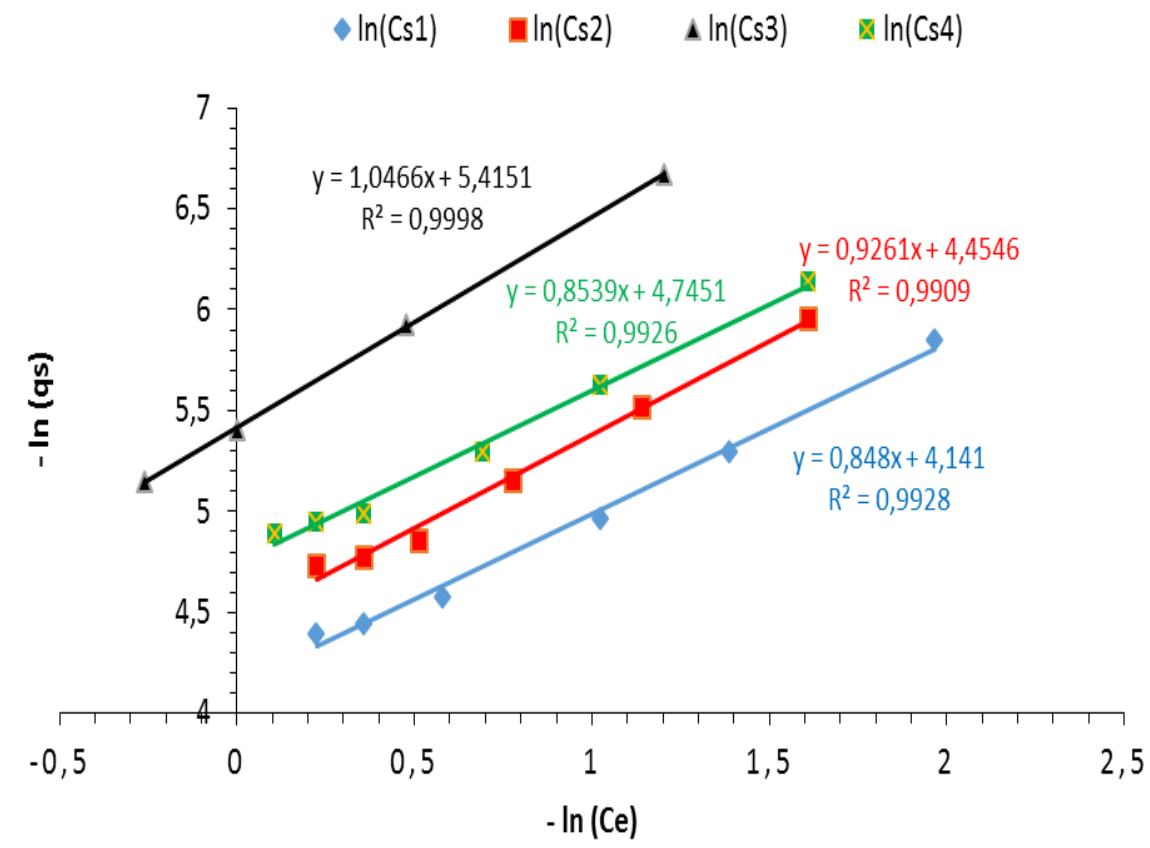

Figure 7. Freundlich adsorption isotherm for MFD adsorbed on Soils $\left(\right.$ Temperature $=22^{\circ} \mathrm{C}$, Ratio $=40$ g.L $\mathrm{L}^{-1}$, Time contact $=30 \mathrm{~h}$, natural $\mathrm{pH}$ of soil)

The results of the Langmuir model indicated that the maximum adsorption capacity Csmax of MFD in soil 3 is not calculable, similarly, the $\mathrm{K}_{\mathrm{L}}$ parameter the Langmuir derived using Csmax could not be determined, probably due to the weight of the points of the isotherm corresponding to the very low concentrations of MFD. The Csmax concentrations predicted by the Langmuir model in soil 1,2 and 4 are systematically lower than the adsorbed quantities corresponding to an introduced MFD concentration of $5.0 \mathrm{mg} . \mathrm{L}^{-1}$ (Figure 4). However, the Csmax concentrations that must logically be greater than the adsorbed quantities determined when the isotherms are drawn. Thus, the values of Csmax determined for the MFD are devoid of meaning. The comparison of the regression coefficients shows that for all soils the Freundlich model describes better the adsorption isotherms of the MFD than the Langmuir model. Indeed, the Freundlich model assumes that the adsorption of molecules at the solid-solution interface takes place on heterogeneous surfaces with different types of adsorption sites, while that of Langmuir describes an adsorption-taking place on homogeneous sites ${ }^{42}$. In a medium as heterogeneous as soil, Langmuir approach to uniform adsorption seems less realistic.
The value of the Freundlich exponent (n) is close to unity for the soil 3. According to the classification ${ }^{38}$, the isotherm obtained for soil 3 is linear, indicating the absence of competition between the adsorption molecules those of solute and solvent. The value of (n) greater than one, characterized the adsorption (MFD) under soils 1, 2 and 4 of nonlinear adsorption isotherm in the range of studied concentrations. Finally, since the values of (n) differ greatly for the studied soils and the $\mathrm{K}_{\mathrm{F}}$ size depends on this value, it is not possible to compare the $\mathrm{K}_{\mathrm{F}}$ values characterizing the adsorption of the MFD on the different soils ${ }^{43}$.

In order to compare the adsorption of MFD by the studied soils, the isotherms were considered only in their linear part, ie at low concentrations $\mathrm{Ce}(\mathrm{Ce}<$ $0,7 \mathrm{mg}$. $\left.\mathrm{L}^{-1}\right)$. This range of low concentrations includes the agronomic dose of MFD $\left(\approx 0.125 \mu \mathrm{g} . \mathrm{g}^{-1}\right.$ corresponding to $0.2 \mathrm{~kg} \cdot \mathrm{ha}^{-1}$, considering that one hectare of soil represents a mass of 1600 tons). Under these conditions, the evolution of the adsorbed concentrations as a function of equilibrium $\mathrm{Ce}$ concentrations (Figure 8) is correctly described by linear regression $\left(\mathrm{R}^{2} \geq 0.983\right)$. The observation of a linear relation allows us to determine the distribution coefficient $\mathrm{Kd}$. Table 5 gives the values of the coefficients $\mathrm{Kd}$ and $\mathrm{Koc}$ of the four soils.

Table 5. Values of the distribution coefficient $K_{d}$ and constant Koc, obtained by linearization of the adsorption isotherms MFD.

\begin{tabular}{|l|c|c|c|c|}
\hline Soils & Soil 1 & Soil 2 & Soil 3 & Soil 4 \\
\hline Coefficient Kd (L/kg) & 18.3 & 12.8 & 4.30 & 9.70 \\
\hline Coefficient Koc (L/kg) & 508.3 & 400 & 239 & 441 \\
\hline
\end{tabular}


The analysis of the results shows that soil 1 has a relatively high affinity for MFD compared to other soils. The adsorption decreases significantly in the following order: Soil 1> Soil 2> Soil 4> Soil 3, which is consistent with the decrease in MO levels in these soils. Shan et al. suggested grouping the herbicide by Koc values and concluded that Koc values less than 50 as the highest mobility group and those having Koc values between 50 and 550 as medium mobility group 43.

All the Koc values observed in this study suggested that MFD had moderately to high mobility in different soil types, which might result in a leaching problem working with MFD.

\section{$\bullet \operatorname{Cs} 1 \quad \square \operatorname{Cs} 2 \quad \Delta \operatorname{Cs} 3 \quad \triangle \operatorname{Cs} 4$}

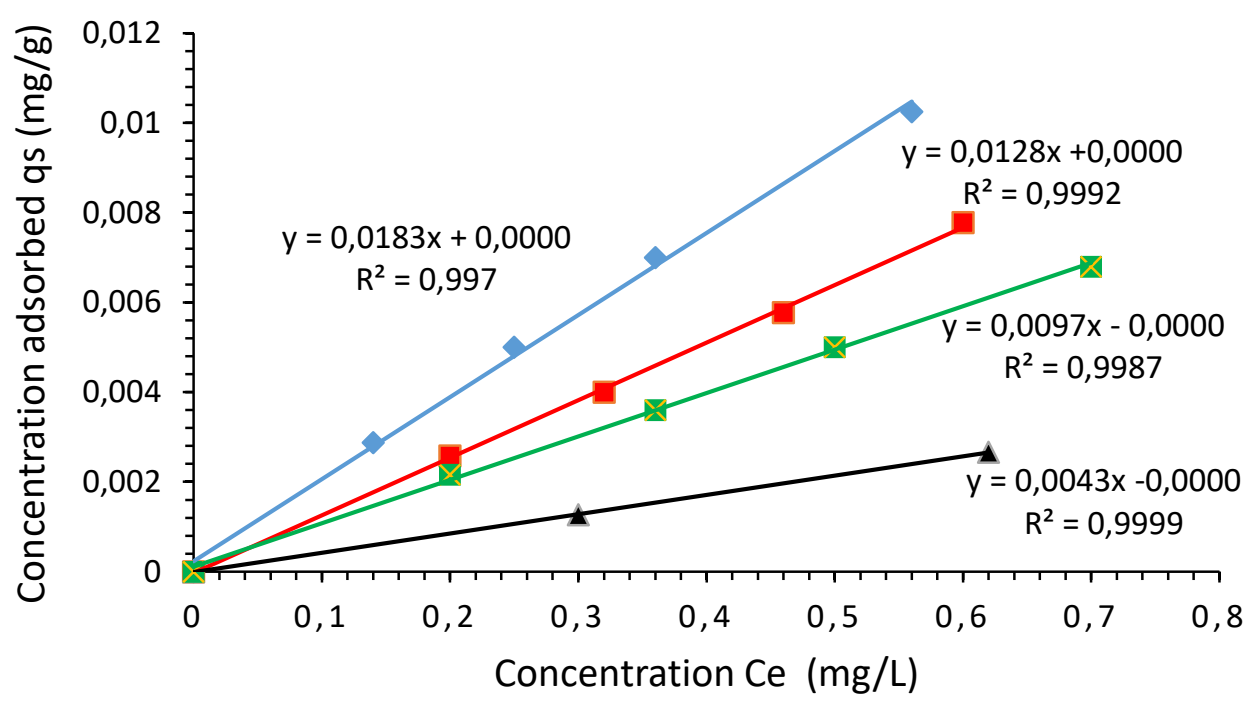

Figure 8. Evolution of the adsorbed concentrations as a function of equilibrium $\mathrm{Ce}$ concentrations $(\mathrm{Ce}<0,7 \mathrm{mg}$. $\mathrm{L}^{-1}, \mathrm{~T}=22^{\circ} \mathrm{C}$, Ratio $=40 \mathrm{~g} / \mathrm{L}$, Time contact $=30 \mathrm{~h}$, natural $\mathrm{pH}$ of soil $)$

\section{Desorption isotherms}

Desorption study of herbicide is very important as it controls the release rate, mobility of herbicide in soil and the treatment processes for the contaminated soils. The desorption of MFD was carried out from the initially treated soils with an MFD concentration of $5.0 \mathrm{mg}$. $\mathrm{L}^{-1}$, the highest concentration used by the adsorption isotherm tracing. The evolution of the cumulative quantities of MFD desorbed during the four successive desorption is given in Figure 9.

The figure shows that the desorbed cumulative amounts of MFD increases and the desorbed quantities gradually decrease during successive desorption. In order to compare the four soils, the amounts of total MFD desorbed after four successive desorptions were expressed as a percentage of the quantities initially adsorbed (Table 6).

The total quantities desorbed after four desorptions are between $38.5 \%$ and $73.1 \%$ of the amounts of initially adsorbed MFD. The desorption was higher in soil 1 , followed by soil 2 , soil 4 and the lowest was observed in soil 3. This is related with the high organic matter content in soils, which enhanced the sorption capacity. The desorption of herbicides from the soils was high; thus they will be easily leached or moved into the groundwater system particularly in highly weathered soils. The desorption process occurs due to the low bonding between MFD molecules and active sites in soil resulting in high release rate.

Table 6. Values of the total amount and relative amount desorbed of the adsorption isotherms MFD in soils.

\begin{tabular}{|c|c|c|c|}
\hline & $\begin{array}{l}\text { Amount } \\
\text { adsorbed (mg.g-1) }\end{array}$ & $\begin{array}{l}\text { Total amount } \\
\text { desorbed (mg.g-1) }\end{array}$ & $\begin{array}{l}\text { Relative } \\
\text { Amount desorbed (\%) }\end{array}$ \\
\hline Soil 1 & 0.10 & 0.059 & 59.0 \\
\hline Soil 2 & 0.09 & 0.050 & 55.6 \\
\hline Soil 3 & 0.04 & 0.015 & 37.5 \\
\hline Soil 4 & 0.08 & 0.042 & 52.5 \\
\hline
\end{tabular}




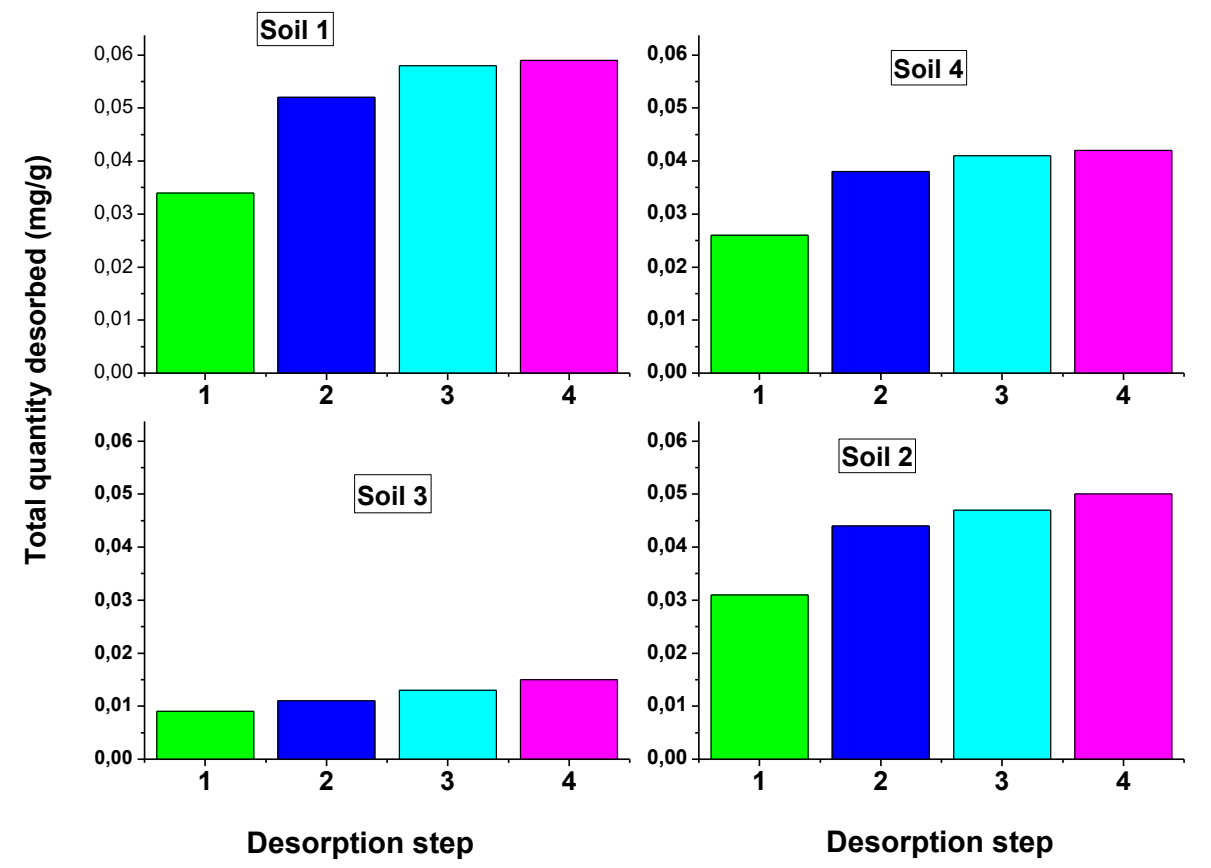

Figure 9. Evolution of the cumulative quantities of MFD desorbed during the four successive desorptions

\section{Conclusion}

This study contributes to the understanding of Mefenpyr-diethyl adsorption-desorption process in the four types of agricultural soil of Morocco. The study of the adsorption kinetics has shown that the MFD adsorption process occurs during the first minutes of contact and become slow down with the stirring time to reach equilibrium after $30 \mathrm{~h}$. The adsorption and desorption being greater in soils with higher soil organic and clay content. The Freundlich equation fitted very well the equilibrium data over the studied entire concentration range. The results obtained in the present study demonstrate that the organic matter/clay content as a controlling factor for application of MFD in the soil. Therefore, these findings will enable the prediction of persistence and mobility of MFD in the soil with similar soil properties.

\section{Acknowledgements}

Authors of this study tank technicians GC/MS of the Anti-Poison Centre and Pharmacovigilance of Morocco for technical assistance.

\section{References}

1- M. K. Kettles, S. R. Browning, T. S. Prince and S. W. Horstman, Environ Health Perspect, 1997, 105, 1222-1227.

2- $\quad$ M. Arias-Estévez, E. López-Periago, E. Martínez-Carballo, J. Simal-Gándara, J. C. Mejuto, et al., Agr. Ecosyst Environ, 2008, 123, 247-260.

3- $\quad$ L. Cox, R. Celis, M. C. Hermosín, J. Cornejo, J. Agric. Food Chem., 2000, 48, 93-99.
4- Caroline Cox, A new list of carcinogenic pesticides used in food, Journal of Pesticide Reform, 1992, 12, No. 4, Winter 1992, pp. 28.

5- E. Hacker, H. Bieringer, L. Willms, W. Rosch, H. Kocher and R. Wolf, Journal of Plant Diseases and Protection,2000, 493-500.

6- A. Chnirheb, M. Harir, B. Kanawati, A. Fekete, M. El Azzouzi, N. Hertkorn and P. SchmittKopplin, Analytical and Bioanalytical Chemistry, 2010, 398 (5), 2325-2334.

7- A. Chnirheb, M. Harir, B. Kanawatil, M. El Azzouzi, I. Gebefugil and P. Schmitt-Kopplin, Journal of Environmental Sciences, 2012, 24 (9), 1686-1693.

8- Y. Liu, Z. Xu, X. Wu, W. Gui and G. Zhu, Adsorption and desorption behavior of herbicide diuron on various Chinese cultivated soils, J Hazard Mater, 2010, 178, 462-468.

9- P. Singh, C. R, Suri and S. S. Cameotra, Isolation of a member of Acinetobacter species involved in atrazine degradation, Biochem Biophys Res. Commun, 2004, 317, 697-702.

10- C. Flores, V. Morgante, M. González, R. Navia and M. Seeger, Adsorption studies of the herbicide simazine in agricultural soils of the Aconcagua valley central Chile,

J. Chemosphere, 2009, 74(11), 1544-1549.

11- C. Wu, S. Zhang, G. Nie, Z. Zhang and J. Wang, Adsorption and desorption of herbicide mono sulfuron- ester in Chinese soils, J. Environ Sci. (China), 2011, 23, 1524-1532.

12- S. S. Salih, T. K. Ghosh, Preparation and characterization of bioadsorbent beads for chromium and zinc ions adsorption. Cogent Environmental Science, 2017, 3, 1401577.

13- S. S. Salih, T. K. Ghosh, Adsorption of Zn (II) ions by chitosan coated diatomaceous earth. 
International journal of biological macromolecules, 2018, 106, 602-610.

14- S. S. Salih, T. K. Ghosh, Preparation and Characterization of Chitosan-Coated Diatomaceous Earth for Hexavalent Chromium Removal. Environmental Processes, 2018, 5, 23-39

15- S. S. Salih, T. K. Ghosh, Highly efficient competitive removal of $\mathrm{Pb}$ (II) and $\mathrm{Ni}$ (II) by chitosan/diatomaceous earth composite. Journal of environmental chemical engineering, 2018, 6, 435-443.

16- R. Kanissery, B. Gairhe, D. Kadyampakeni and M. Kelly, Herbicide - Nutrient Interactions in Soil: A Short Review, Agri Res \& Tech: Open Access J, 2018, 15(2), 555951.

17- K. El khattabi, A. Bouhaouss, C. Perrin-Ganier and M Schiavon, Agronomie EDP Sciences, 2004, 24 (4), 177183.

18- K. El khattabi, R. Bchitou, A. Bouhaouss, S. A. Bufo, L. Scrano and M Schiavon, Phys Chem News, 2009,45, 101-106.

19- S. Oufqir, M. El Madani, M. Alaoui El Belghiti, A. Zrineh and M. El Azzouzi, J arabjc, 2013, 11, 030.

20- S. Azarkan, A. Peña, K. Draoui and C. I. Sainz Díaz, Applied Clay Science, 2016, 123, 37-46.

21- D. A. Laird, P. Y. Yen, W. C. Koskinen, T. R. Steinheimer and R. H. Dowdy, Environmental Science \& Technology, 1994, 28, 1054-1061.

22- Z. Tang, W. Zhang and Y. Chen, Journal of Hazardous Materials, 2009,166, 1351-1356.

23- Centre d'expertise en analyse environnementale du Québec, Détermination de la granulométrie : méthode gravimétrique par tamis. MA. 100Gran 1.0, Ministère de l'Environnement du Québec 1-8(2005).

24- Centre de coopération internationale en recherche agronomique pour le développement. Analyse granulométrique par sédimentation, Méthode à la pipette sur granulomètre automatique1-28(2004).

25- OECD, Guidelines for testing of chemicals, Environment Directorate, Paris, France. Section 1, 2000, (106).

26- R. D. Wauchope, S. Yeh, R. Kloskowski, K. Tanaka and B. Rubin, Pesticide Management Science, 2002, 58(5), 419-445.
27- L. Alder, K. Greulich, G. Kempe and B. Vieth, Mass Spectr Rev 5, 2006, 838-865.

28- A. El Boukili, A. El Bazaoui, A. Soulaymani, R. Soulaymani-Bencheikh, M. Taibi and A. El Hourch, J Mater Environ Sci., 2015, 6 (9), 2386-2391.

29- O. Hamdaoui, E. Naffrechoux, Journal of Hazardous Materials, 2007, 147, 401-411.

30- H. Freundlich, H. Kapillarchemie and Leipzig, Akademische Verlagsgesellschaft M B H, 1909, 591pp.

31- J. W. Hamaker, J. M. Thompson and Marcel Dekker, Organic Chemicals in the Soil Environment, New York, 1972, 1, 49-144.

32- A. C. D. Newman, The specific surface of soils determined by water sorption, J Soil Sci., 1983, 34, 23-32.

33- J. M. Bigham, D. C. Golden, S. W. Buol, S. B. Weed and L. H. Bowen, Soil Sci. Soc Am J, 1978, 42, 825- 830.

34- D. G. Schulze and U. Schwertmann, Clay Miner, 1984, 19, 521-539.

35- C. Feller, E. Schuller, F. Thomas, J. Rouiller and A. J. Herbillon, Soil Sci., 1992, 153, 293-299.

36- N. Singh, H. Kloeppel and W. Klein, J. Environ Sci Health B, 2001, 36, 397-407.

37- C. Moreau and C. Mouvet, J. Environ Qual., 1997, 24, 416-424.

38- C. H. Giles, T. H. MacEwan, S. N. Nakhwa and D. Smith, Journal of the Chemical Society, 1960, 3973-3993.

39- M. F. Fernandez-Perez, F. Flores-Cespedes, E. Gonzalez-Pradas, M. Villafranca-Sanches, S. Perez-Garcia and F. J. Garrido-Herrera, Journal of Agricultural and Food Chemistry, 2004, 52, 3888-3893.

40- A. Valverde-Garcia, E. Gonzalez-Pradas, M. Villafranca-Sanchez, D. Del Rey-Bueno and A. Garcia- Rodriguez, Soil Science Society of America Journal, 1988, 52, 1571-1574.

41- D. K. Sharma, A. Gupta and R. Kashyap, Toxicological \& Environmental Chemistry, 2011, 93, 1319-1331.

42- G. Limousin, J. P. Gaudet, L. Charlet, S. Szenknect, V. Barthes and M. Krimissa, Applied Geochemistry, 2007, 22, 249-275.

43- K. A. Shahzad, R. Naghmana and A. Sundus, Eurasian J Soil Sci., 2016, 5 (1), 1-12. 